\title{
LA ORGANIZACION MUNICIPAL DE ALICANTE ss. XIV-XV
}

\author{
Juan A. Barrio Barrio \\ Universidad de Alicante
}

Las bases de la organización municipal de Alicante durante los siglos XIV y $X V$, hay que situarlas en la incorporación de la villa al reino de Valencia y la recepción del sistema político, administrativo y legislativo que regia en $\mathrm{Va}$ lencia y recogido en las disposiciones forales.

Alicante en esta época tuvo una administración local plenamente «valenciana" (1) y que se asemeja a la existente en otros municipios de la cuenca mediterránea, especialmente los italianos (2).

\section{LAS BASES DEL GOBIERNO MUNICIPAL VALENCIANO}

A la cabeza del municipio valenciano se situaba el Justicia, un magistrado con atribuciones judiciales de primera instancia, juez ordinario con jurisdicción sobre el término y encargado del orden público (3).

Los Jurados, en número variable según los municipios, ejecutaban las principales tareas del gobierno municipal, como tasar los precios, controlar las obras publicas, etc., y llevar propuestas de gobierno al Consell, que era, en ocasiones, quien tenía que tomar por mayoría simple determinadas decisiones. 
En la base de la administración se situaba el Consell, un consistorio consultivo y que decidía sobre determinados ámbitos. Podía ser abierto, con la reunión de toda la asamblea municipal en un Consell general abierto, o una asamblea cerrada formada por un número determinado de miembros que se reunían periódicamente en un Consell general cerrado.

Los elementos principales del sistema político del municipio valenciano a fines del siglo XIII se recogen en la legislación de Jaime I y Pedro III (4). En esta fecha la composición básica del gobierno ciudadano la constituía un Justicia, varios jurados, y un Consell como órgano de representación de la Universitas. La duración del cargo era anual, y la elección se realizaba en fechas distintas para cada uno de los oficios.

Para la elección del Justicia Jaime I estableció en 1266 un sistema que prevaleció durante mucho tiempo. Los jurados y prohombres elegían cada año el tercer día antes de Navidad tres probi homines, y presentaban al rey dicha terna, si éste estaba en Valencia, y en su lugar al Baile, que elegía el nuevo Justicia (5). La baja nobleza tuvo acceso al cargo de Justicia en tiempos de Jaime I. En la terna que la ciudad debía presentarle con el nombre de tres prohombres, uno de ellos tenía que ser un caballero elegido por miembros de su propio grupo (6). Los elegidos, después de su mandato, no podían desempeñar el cargo de Justicia durante tres años (7).

Pedro III fijó en las Cortes de 1283 el calendario electoral para dotar los cargos municipales (8), que se mantendrá en el futuro con algunas modificaciones, quedando fijada la elección del Justicia en vísperas de Navidad, la de los jurados en Pentecostés, y la del Almotacén el 29 de septiembre, día de San Miguel. En la elección de oficiales introdujo una modificación: concedió un sistema electoral de cooptación indirecta, a través de una insaculación simple, por el procedimiento de extracción al azar de redolinos, bolitas de cera donde están inscritos los nombres de los candidatos, que se implantó para la elección de Justicia, jurados y Mustaçaf. Para la elección de nuevos jurados, los jurados en curso junto a cuatro prohombres por parroquia nombraban doce candidatos, uno por parroquia, que el azar reducía a cuatro, que ocupaban el cargo durante el siguiente año. El rey se reservó la facultad de designar al Justicia de entre los nombres de una terna. La elección de los nombres de la terna se realizaría por el procedimiento de redolins, y los doce candidatos se elegían de igual forma que para la elección de jurados (9).

Finalmente, en 1321, Jaime II ordenó la escisión del Justicia valenciano en dos magistraturas, Justicia Criminal y Justicia Civil (10), e introdujo a la baja nobleza caballeros y homens de paratge en el resto de órganos del gobierno municipal (11). Un fuero de Alfonso IV de las Cortes de 1329 regulaba la 
alternancia en los oficios de ciudadanos y caballeros, de forma que si un año el Justicia Criminal era caballero, el Justicia Civil debía ser ciudadano, y al año siguiente al revés, con un reparto respecto a los jurados, en los que hubo mayor presencia ciudadana, casos de Valencia y Orihuela (12). En Orihuela la escisión del Justiciazgo en dos magistraturas se produjo en 1336 (13) lo que afectó al resto de villas de esa Procuración General, caso de Alicante, que dependian ahora de un magistrado superior: el Justicia Criminal de Orihuela, al que, podrian apelar los vecinos de dichos municipios.

Las bases de la administración municipal, quedaron establecidas con unos órganos de gobierno elegidos entre un número reducido de electores, con un sistema de insaculación simple, de forma que el elegido venía determinado por el azar, pero con una mecánica regulada que establecía una alternancia en el poder por grupos sociales, principalmente entre la baja nobleza y el grupo de ciudadanos.

La potenciación del poder real se realizó a través de la segregación de la jurisdicción del Justicia originario, por la creación del Justicia Civil y los Justicias de las villas reales, junto a la creación de nuevos oficiales reales. Según Pérez García (14), la aparición del Justicia Criminal en 1321 supone un reforzamiento del poder del monarca. Esta fragmentación administrativa y política se agudizaría con la creación de la nueva unidad administrativa por Jaime II, lo que supuso una duplicación, en menor escala, de la unidad administrativa, que ya existía en la ciudad de Valencia, sobre un territorio en el que se crea una verdadera capital, Orihuela, de la que pasarán a depender las villas reales de la Procuración, al igual que sucedía con la dependencia de otras villas respecto a la ciudad de Valencia, y en relación con su Justicia Criminal. Uno de los elementos que traslucen esta duplicación es el hecho de que la ciudad de Valencia tenía que presentar su terna de candidatos para la designación de cargos al rey o, en su ausencia, al Baile general. Orihuela tenía que presentar sus candidatos al Baile general del reino de Valencia dellà Sexona, y en ausencia de éste al Baile local de Orihuela (15).

\section{2. ÓRGANOS DE GOBIERNO EN LA VILLA DE ALICANTE}

En Alicante las primeras manifestaciones del futuro organigrama municipal se sitúan en 1296 con la concesión de un privilegio de Jaime ll sustituyendo la administración municipal castellana de alcaldes y alguaciles que hasta la fecha regía, por el sistema de Justicia, jurados y Almotacén, con la salvedad de realizar la elección anual según la forma en se que elegían los cargos anteriores. $Y$ con la prohibición expresa de que los judíos desempeñen car- 
gos públicos en la villa (16). En junio de 1308 Jaime ll disponía que el Justicia de Alicante debía atenerse en las causas judiciales a los fueros de Valencia (17). El mismo mes se realizó la anexión formal de Alicante al reino de Valencia y la recepción de los fueros por los que se regía la ciudad y el reino junto a diez privilegios específicos concedidos por Jaime II a la villa de Alicante en los que se fijó el salario y competencias del Justicia, la prohibición de ocupar oficios municipales a caballeros y generosos, y el derecho de ocupar cargos sólo a los vecinos de Alicante (18), que recibió unos órganos de gobierno y unos mecanismos de dotación de los mismos sobre la base de los privilegios de 1266 (Jaime I) y 1283 (Pedro III).

A partir de este año en la villa de Alicante rigió un sistema de gobierno basado en los fueros de Valencia, que en esta fecha habian establecido las bases de lo que sería el gobierno municipal valenciano hasta su abolición en el siglo XVIII (19).

El Justicia se situaba a la cabeza del municipio en la villa de Alicante durante al época foral. Era juez ordinario en primera instancia, y tenía facultades de policía y orden público. Debia conocer todas las causas civiles, criminales y fiscales que se suscitaran en el término (20). Gozaba de la facultad de absolver las calonías como lo hacía el Justicia de Valencia (21), que podía hacer gracia, remisión o perdón de multas, sobre todo tipo de sanciones civiles y criminales, excepto aquellos delitos graves penados con mutilación o muerte (22). Presidia las sesiones del Consell, y debía juzgar según el parecer de los prohombres, posteriormente Consell, que validarian jurídicamente las sentencias del Justicia (23).

La corte del Justicia entre sus obligaciones tenía que disponer de una taula de les scriptures, donde los vecinos de la villa pudiesen validar ante los notarios de la corte cualquier escritura (24). Jaime I estableció la gratuidad de las copias y traslados de cartas o escrituras realizadas en la cort del Justicia (25). En 1329 las Cortes de Valencia fijaban los emolumentos que se cobrarían en la corte del Justicia, indicando los precios correspondientes a cada tipo de escritura (26).

El Justicia como el resto de oficiales contaba con un lugarteniente, que a diferencia de lo que sucedía en Valencia, en las villas de la Gobernación dellà Sexona no era ocupado por un miembro del común, ya que en Orihuela en el siglo XV la lugartenencia de Justicia criminal y civil se dotaba con miembros de la mano mayor (caballeros) y de la mano media (ciudadanos) (27). 
El salario del Justicia fue fijado en 1308 por Jaime II en 600 sueldos (30 libras) y el de su asesor jurídico en 300 (15 libras) (28). Los ingresos de la corte del Curia venían determinados por el tercio de las multas y penas impuestas sobre los establiments (prohibición de jugar, entrar ganado en coto cerrado, etc.) ordenados por el Consell, y fijados por pregón público. Otro ingreso recogido en fueros era el quart -el cuarto- de las deudas que el condenado debía abonar al Justicia, junto a los gastos del proceso (29). En Alicante la pena del quart fue reducida por Jaime II a la décima parte de la deuda en litigio (30). Estos ingresos eran administrados por el Justicia, tesorero y responsable ante el rey de las cuentas de su gestión anual, y revisadas por el Baile, como representante real (31). Pero este sistema no parecía ofrecer garantías suficientes a la corona, que actuó en el ecuador del siglo XV pidiendo a la ciudad de Orihuela, en 1445, las cuentas de la administración de los Justicias durante los últimos cuarenta años. Solicitud que alarmó a los dirigentes del municipio, que suplicaron que el control de las cuentas se efectuase sólo sobre los últimos diez años (32). Tres años después don Juan, lugarteniente general del reino, requería al Baile general del reino de Valencia dellà Sexona para que actuase con diligencia sobre las cuentas de los últimos cuarenta años de los justicias de Orihuela y Alicante, ante la sospecha de fraude al patrimonio regio por ocultación en las mismas de las penas y multas cobradas, de las que un tercio pertenecían al rey (33).

Las limitaciones que el oficio de Justicia conoció a lo largo del siglo XV se manifiestan con claridad en Alicante a partir de la segunda mitad de esta centuria. El intento de muerte contra Alfonso Rebolledo, alcaide del castillo de Alicante (34), y el asesinato de Nicolau Nomdedeu, lugarteniente del Justicia, pusieron en evidencia la incapacidad de este último para garantizar el orden público en la villa, donde quedó en entredicho su potestad, reconocida en fueros (35), sobre las licencias para llevar armas y la custodia sobre las armas confiscadas, ante la actuación del Gobernador, acusado por el Justicia de conceder guiatges para portar armas a diversos delincuentes, entre los que se encontraban los supuestos asesinos, y de sacar de la prisión a los que ya había detenido, en detrimento de su jurisdicción criminal reconocida en fueros y privilegios sobre los crímenes y delitos cometidos en el término. Esta situación de inestabilidad del poder municipal, repercutió en la eficacia de las guardias nocturnas - cuya organización y dirección eran competencia del Justicia- que muchos se negaban a realizar ante los evidentes peligros a que daba lugar la situación (36). El hecho de que en algunas causas judiciales suscitadas en la villa el Justicia Criminal de Orihuela obtuviese comisión para intervenir, mermaba la jurisdicción del Justicia de Alicante (37), junto a la dinámica del poder central, que delegaba las causas judiciales en téc- 
nicos en leyes y reforzaba su poder a través de la intervención de juristas cualificados, en detrimento de los oficiales municipales, con la pérdida del carácter popular de la justicia municipal y a favor de la tecnificación de la misma (38).

La Juradería de Alicante estaba formada por dos jurados, que eran jueces en las causas sobre imposiciones tributarias y derechos económicos, y las sentencias dictadas por ellos en estas causas no podian ser apeladas (39). Tenían competencias, en general, sobre la administración y gestión de los bienes económicos del término, como tasar los precios, gestionar la política de abastecimiento de productos alimenticios, licencias de importación y exportación de determinados productos como el trigo y el vino, etc (40).

El Mustaçaf, que contaba con un lugarteniente, se ocupaba de la inspección de pesos y medidas utilizadas en la villa en las transacciones mercantiles (41), además de tener que observar la ejecución de la reglamentación sobre vestimentas (42). Las atribuciones de este oficial mermaron la jurisdicción del Justicia en competencias civiles y criminales (43), ya que el Mustaçaf tenía jurisdicción específica sobre aspectos urbanísticos, control de pesos, medidas, precios y calidad de los alimentos, así como de los productos elaborados por los artesanos, cuestiones sobre las que tenía competencias plenas ya que el Justicia y los oficiales reales no podían entrometerse (44). Las tensiones que se dieron en Alicante por las diferentes atribuciones jurisdiccionales también afectaron a este oficio. En 1477 Francés Celler, Mustaçaf, era apresado, multado y encarcelado por el Justicia de Alicante por unos problemas de jurisdicción que había tenido con él (45). Celler fue apartado del cargo e inhabilitado por el Justicia para ejercer oficios municipales, al entender éste que un procesado perdía sus derechos cívicos y no podía ejercer oficio público. Dos años después, ante las alegaciones del encausado, Fernando II sentaba jurisprudencia al ordenar que Celler fuese habilitado para ejercer oficios municipales en la villa mientras no hubiese sentencia definitiva condenatoria (46).

El Clavario administraba las cuentas del Consell, anotando en un libro las partidas de gastos e ingresos. Tenía que recibir entre otros ingresos, el pago de los impuestos municipales, como la sisa, que se arrendaba anualmente al mejor postor (47). La gestión del Clavario, al finalizar el ejercicio anual, estaba fiscalizada por los contadores nombrados por el Consell. Este procedimiento de fiscalización de la gestión no fue suficiente, ya que Juan II habia sido informado de los errores que se habían encontrado en los libros de cuentas del Clavario, a pesar de que habian recibido el visto bueno de los contadores del Consell, uno de los síntomas evidentes de la mala gestión de la ha- 
cienda municipal, mal endémico que afectó a la mayoría de municipios valencianos. Además de la inadecuada gestión, el lastre de las deudas pesaba sobre las arcas municipales, ante la desafección del Clavario que no actuaba con la dureza suficiente para cobrar a los arrendatarios de los impuestos municipales las cantidades pertinentes. No obstante, el oficio de Clavario adquirió singularidad desde las ordenanzas de 1459 , en que se fijaba una fecha diferente para su elección, el 4 de febrero, y sobre todo desde el privilegio de 1479 de Fernando II por el que estableció que el Clavario debía elegirse de forma diferente al resto de oficiales. El 4 de febrero el Justicia y los dos jurados elegirían al nuevo Clavario por el sistema de redolins, mientras que para el resto de oficios se mantuvo el sistema de extracción de «sac i sort" de las bolsas mayor y menor, previa habilitación, fijado en 1459 (48). En esta línea se sitúa el privilegio de 1502 que concede al Clavario facultad sobre las rentas y censales de la ciudad, en detrimento de los jurados que veían disminuidas sus competencias (49).

El Sobrecequier se hacía cargo de la organización del riego en la huerta, y tenía jurisdicción sobre los pleitos suscitados por el aprovechamiento del agua de riego (50).

El Consell, como en muchos municipios valencianos, fue de tipo asambleario o abierto hasta el siglo XV. Aunque hemos de matizar que en la segunda mitad del siglo XIV ya existía un Consell semiabierto, formado por los prohomens de la mano mayor, mediana y menor. Se diferenciaba del Consell abierto en que no asistían a sus reuniones el total de los vecinos, sino un grupo escogido de entre cada una de las manos, aunque desconocemos el criterio seguido para determinar quiénes y cuántos eran dichos prohombres. Se diferenciaba del Consell cerrado, en que éste está formado por un número específico de consellers, que reciben esta denominación y oficio al ser elegidos en la elección anual para cubrir dichos cargos.

Destacar, por tanto, que este Consell semiabierto ya tiene las características selectivas de lo que será luego el Consell cerrado. Su convocatoria se realizaba mediante pregón público para acudir a la iglesia de San Nicolás a Consell general para deliberar con el Justicia y jurados los asuntos concernientes al gobierno de la villa. Eran excluidos, por tanto, de esta reunión las minorías étnicas como judíos y mudéjares, los vecinos que habitaban los arrabales y los que no formaban parte del grupo de prohombres (52).

Un primer intento de crear un Consell cerrado se remonta a 1382 cuando el Infante don Juan, lugarteniente general, otorgó a la villa de Alicante una disposición, por la que se creaba un Consell general cerrado formado por 
24 miembros, 8 por cada una de las manos mayor, mediana y menor respectivamente, y un Consell especial de 12 miembros con igual proporción en su composición (53). Este privilegio fue anulado cuatro años más tarde, en 1386, por Pedro IV ante las protestas que habia recibido por los desórdenes y desgobierno en que se encontraba la villa ante las dificultades de reunir los 24 consellers para celebrar sesión plenaria, ya que éstos estaban en sus heredades de la huerta, situadas fuera de las villa. Pedro IV ordenaba volver a la situación anterior al privilegio de 1382 (54).

La creación definitiva del Consell cerrado se produce en 1459, con la designación de un órgano formado por veinticuatro miembros, dieciocho de la mano mayor, y ocho de la menor.

El Consell tenía entre sus atribuciones la facultad de aprobar los establiments en materia de orden público, y validar jurídicamente las sentencias pronunciadas por el Justicia. Sin el consentimiento del consistorio no podian ser emitidas sentencias o absoluciones (55).

El Escribano del Consell era un notario que se hacia cargo de las escrituras del municipio, actas de las sesiones del Consell, cartas, etc. Debía ser nombrado por el propio Consell, que juzgaría y valoraría las aptitudes de los notarios aspirantes al cargo. Como en el resto de los oficios, no fue extraña la intromisión real, hasta el punto de nombrar Juan II en 1474 a Francesc Rius como escribano del Consell de Alicante, lo que motivó las pertinentes protestas de las autoridades locales (51).

\section{LA PROVISIÓN DE CARGOS MUNICIPALES: LOS REQUISITOS PARA DESEMPEÑAR LOS CARGOS. LA MECÁNICA ELECTORAL}

En este apartado haremos una descripción somera de los principales cambios e incidencias, sobre la provisión de cargos, a través del estudio de los requisitos exigidos para poder acceder a los oficios municipales, y la mecánica electoral para dotarlos en la villa de Alicante durante el período estudiado.

\subsection{Los requisitos para desempeñar los cargos}

Desde la creación del Curia de Valencia por Jaime I hasta las reformas municipales efectuadas por Fernando II, la corona fijó los requisitos mínimos para desempeñar los cargos municipales, reservando a una élite de prohombres el control de la res pública, del que estaban descartadas las mujeres que no tenian acceso a los oficios públicos. 
Jaime I ya limitó el acceso al Justiciazgo a los vecinos del municipio, excluyendo a los de los arrabales, y vedando el cargo a sarracenos, judíos y usureros públicos (56).

Durante los siglos XIV y XV se ampliaron los requisitos mínimos, para acceder a los oficios municipales. Hasta 1426 el tope de edad para acceder a los oficios municipales en el reino, se habia establecido en veintidós años, y desde esta fecha se prohibió el acceso a los menores de veinticinco años, a los solteros y «a los naturales del reino cuyo avecindamiento sea menor de cinco años y a los extranjeros con un vecindazgo inferior a los veinte años» (57).

Martín I fijó como requisito imprescindible, para acceder a los oficios de Justicia, Jurado y Mustaçaf en la villa de Alicante, la posesión de un caballo por valor de entre 25 y 30 florines, y prohibió a las mujeres cuyos maridos no tuviesen dichos caballos portar piedras preciosas en sus prendas, oligarquizando de este modo la vida social y política de la villa. Privilegio que confirmó en 1426 Alfonso $\vee(58)$, que endureció los requisitos restrictivos, imponiendo la obligación de tener el corcel medio año antes de la elección y de mantener el caballo durante los dos años siguientes al desempeño del cargo. Como pena fijaba la imposibilidad de acceder a los oficios durante diez años. Y se fijaba la calidad del animal, no pudiendo el candidato presentar «troters aquanees ne que hauren ne facen fahenas (59).

Las Ordenanzas otorgadas por Juan II en 1459 a la villa de Alicante, entre sus novedades especificaban las incompatibilidades para el desempeño de los cargos, prohibiendo desempeñar cargos a los deudores de la villa, a los que mantenían pleitos con el municipio, a los arrendatarios de los derechos municipales, al escribano del Consell y a familiares el mismo año (60).

En Alicante desde 1461 para ocupar cargos, se exigió a los aspirantes tener casa propia y estar casado (61).

Juan II endureció las medidas anteriores hasta el punto de considerar que para la adecuada defensa del reino, era necesario aumentar el número de corceles disponibles para la guerra, y prohibió a aquellos que no tuviesen caballo por valor de 30 florines y capacidad para armarlo, poseer mula para utilizarla como cabalgadura, quedando exentos de esta disposición los mayores de 70 años, a los que permitía disponer sólo de una mula, por lo que si querían tener más debían disponer de un caballo de dicho valor. Confirmó las disposiciones sobre vestimentas fijadas por Martín I, diferenciando las ropas y objetos suntuarios que podían llevar las mujeres casadas según sus maridos tuviesen caballo por valor de 30 florines o no, hasta el punto de marcar la longitud permitida de la falda, para cada caso, quedando dispensadas de estas medidas las mujeres solteras. 
Para acceder al Justiciazgo, Juradería y Mostassafia, confirmó la obligatoriedad de disponer de caballo por valor de 30 florines medio año antes de la elección (62).

\subsection{La mecánica electoral}

La transición del gobierno municipal castellano al valenciano. (1296-1308)

Período confuso del que sólo conocemos, tras la anexión de la villa de Alicante a la corona de Aragón, el cambio en 1296 de los oficiales castellanos, por el sistema de oficiales vigente en Valencia, pero manteniendo el modelo electoral castellano, posible medida de fuerza de Jaime II para mantener el control del municipio en un período de ocupación del territorio.

En 1305 Jaime II solicitó al Concejo de Alicante la concesión para un vecino del cargo de Justicia durante dos años, para que se recuperase de las pérdidas económicas sufridas por un ataque granadino que le obligaba a plantearse la emigración de la villa (63)

La instauración del gobierno municipal valenciano. 1308

Con la concesión en junio de 1308 de los fueros de Valencia, se dispuso la elección de cargos mediante insaculación simple por el sistema de redolins, en las fechas habituales, como se realizaba en Valencia, y designación por el rey del Justicia nominado por la villa, y en su ausencia por el Baile general del reino de Valencia dellà Sexona (64). La concesión en las Cortes de 1329 de los fueros de Valencia a la villa de Alicante, suponía la incorporación de los fueros de 1321 y el aprobado en las mismas Cortes, que regulaban la participación de la baja nobleza en los órganos de gobierno, y su alternancia anual con los ciudadanos en los principales puestos del poder municipal (65). Y que marcaban en Alicante y el resto de municipios valencianos la incorporación de la baja nobleza a los puestos de gestión del municipio y el inicio de un proceso de oligarquización de la vida urbana, que se acentuó durante la centuria siguiente, y que tiene su más clara exponente en las diversas bandosidades o luchas entre facciones nobiliarias que se desarrollaron durante los siglos XIV y XV (66).

Un intento de fragmentación administrativa. 1448

El Baile local de Alicante recibió en 1448 las atribuciones del Baile general de designar al Justicia. Orihuela disfrutaba de dicho privilegio desde 1311, 
en que Jaime II autorizó realizar la confirmación del Justicia de Orihuela, al Baile local en ausencia del Baile general (67).

La concesión de las ordenanzas de «sac i sort». 1459

Alicante recibió en abril de 1459 un nuevo privilegio electoral, llamado de «sac i sort» que ya ha sido estudiado (68).

Una de las novedades más importantes, afectó a la mecánica electoral, esto es, cómo designar los candidatos y de qué forma proceder a la elección. La elección se realizaría por un sistema de extracción al azar, con lo que el aspecto más significativo del cambio es la nominación de candidatos, realizada por una comisión de ocho habilitadores que debían incluir en dos bolsas el nombre de los aspirantes a ocupar cargos. En la mayor irian los candidatos al oficio de Justicia y jurados y en la menor, los de Mustaçaf, Clavario, Sobrecequier, etc. El privilegio concedido, era una serie de capítulos enviados al monarca por las autoridades en ejercicio para su aprobación, por lo que los nombres de la comisión de habilitadores que aparecen en el documento debian estar nombrados, por los oficiales municipales. La habilitación de candidatos debian hacerla en presencia del Consell. El notario del Consell escribía en el libro del consistorio el nombre de los habilitados.

Queremos destacar de este privilegio los aspectos más importantes en comparación con los procedimientos anteriores. Se mantiene el número de oficiales y fecha de elección de los mismos modificando, en unos días, la fecha de elección del Justicia que pasa de celebrarse en vísperas de Navidad a la víspera de Santo Tomás (21 de diciembre). Como novedad se crea un Consell cerrado formado por veinticuatro miembros, dieciséis de la mano mayor y ocho de la menor. La elección de consellers se realizaba el día de Pascua mediante la extracción al azar de los redolins pertinentes de cada bolsa, dieciséis de la mayor y ocho de la menor. Se fijó la fecha de elección del Clavario el 4 de febrero.

Destacar que el Gobernador y el Baile tenían prohibido intervenir en las elecciones, so pena de 1000 florines. Y para la elección de Mustaçaf, si ningún candidato de la bolsa menor reunía los requisitos de idoneidad, posesión de caballo y armas, se extraería de la bolsa mayor. Las ordenanzas tendrian validez durante veinte años.

Finalmente reseñar una referencia importante: los privilegios electorales de sac i sort que concedió el monarca a diversas localidades del País Valenciano (69), se daban a petición de las mismas y pagando una importante cantidad, tal y como sucedió en Orihuela, que abonó 1000 florines de Aragón 
por la concesión del privilegio electoral (70). Lo que suponía un importante desembolso de la oligarquía a cambio de poder controlar el municipio.

Primer fracaso de las Ordenanzas de 1459. Modificación del privilegio

Por las sospechas de actuación fraudulenta de la comisión de ocho habilitadores, que debían elegir los candidatos a ocupar oficios en la villa, se anuló la habilitación realizada. Lo que suponía la suspensión del tercer capítulo de las Ordenanzas, donde aparecían los nombres de los habilitadores denominados por el municipio, que fue modificado por la orden del rey de realizar nueva habilitación de candidatos, por una comisión de ocho habilitadores que él mismo designaría (71).

Reforma de 1461

Un privilegio de 1461 reformaba algunos capítulos de las ordenanzas de 1459. Los principales cambios del privilegio de 1461 afectaron a la forma de sustitución de un oficial en caso de óbito, a la elección de Mustaçaf, al procedimiento de promoción o habilitación de los aspirantes a ocupar oficios (72), y a la incorporación de los jurados salientes al Consell para asesorar sobre la gestión de gobierno.

En caso de muerte de un oficial se debía realizar la elección según el modo acostumbrado, pudiendo el elegido nombrar su propio lugarteniente, y el Justicia, además, su asesor.

Para la elección de Mustaçaf tenían que estar inscritos en el saco menor al menos de tres a seis candidatos con caballo y armas y si no hubiesen suficientes, se debía extraer el nombre del nuevo Mustaçaf del saco mayor.

Para ser promocionado, pasar del saco menor al mayor, o habilitado por primera vez se exigía a los aspirantes tener casa propia y estar casado. Se renovó la obligatoriedad de tener armas y cabalgadura para desempeñar car. gos.

\section{Devolución de la elección}

En 1464 el Baile general del reino de Valencia dellà Sexona, suspendió el privilegio de elección de oficios, ante posibles irregularidades, y realizó una comisión de oficios (el Baile nombraba directamente los nuevos oficiales, por delegación real, hasta que el rey restituía las ordenanzas electorales -el regiment- a la villa de Alicante). Orihuela también conoció esta situación con la anulación del regiment y designación de oficios por el Baile general del reino de Valencia dellà Sexona (73). 
Solicitud de Reforma. 1468.

La inoperancia del sistema aprobado en 1459 y sus respectivas modificaciones se hace patente con la petición realizada por la villa en 1468, en la que los Justicia, jurados y Consell de Alicante solicitan al rey licencia para realizar la elección de oficiales al modo de Valencia con envío de cedas (74). En Valencia el Racional enviaba una lista de personas para la elección de oficiales, que devolvía el rey según su criterio, debiendo ser elegidos los nuevos oficiales sólo de entre los nombres que incluía la lista remitida por el rey (75). Para poder realizar la elección al modo de Valencia, ya que las personas habilitadas eran pocas, el rey anuló la orden que obligaba tener al menos medio año antes de la elección, caballo por valor de 30 florines, para así aumentar el número de personas hábiles. El privilegio que va dirigido al Justicia, jurados y Consell de Alicante, no especifica qué oficial debía preparar la lista, prerrogativa en Valencia del Racional.

\section{Reforma de 1471.}

En 1471 se dotó a Alicante de un nuevo sistema electoral, según la forma vigente en Valencia por parroquias. En Alicante sólo había dos parroquias: la de San Nicolás y Santa María.

Con una diferencia respecto a la de Valencia. Para la elección de jurados en Valencia, a principios del siglo XV, los jurados junto al Racional, síndicos y abogados de la ciudad elegían a los consellers de parroquias (76). En Alicante, los jurados solicitaron elegir directamente a los consellers, pero finalmente se llegó a una concordia por lo que la elección de los consellers de parroquias la harían los jurados y dos homens bons de cada parroquia, Melchor Vallebrera y Guillén Bernat por la de Santa María y Francesch Burgunyo y Pere Pascual por la de San Nicolás. Esto suponía que de los dieciséis miembros de la mano mayor que ocupaban el consell ocho serían elegidos de cada parroquia, al igual que de los ocho de la mano menor, cuatro por parroquia (77). Este privilegio intentaba poner fin a las disputas entre las oligarquías de las dos parroquias por el control del Consell, que ya se habian enfrentado en bandosidades durante el siglo XIV (78).

\section{Reforma de 1477}

Todo parece indicar que desde 1468 en Alicante se siguió un sistema electoral como el de Valencia, hecho que se interrumpe en 1477 con una nueva reforma sobre el privilegio de 1459 (79). El rey nombró nueve habilitadores para realizar nueva insaculación (80). Se renueva la obligación de tener ca- 
ballos y armas. Es una vuelta al privilegio de 1459, confirmado durante seis años.

Hacia la definitiva implantación del sistema electoral de «sac i sort». 1479-1510

En 1479 Fernando Il confirmaba el privilegio de 1477 durante veinte años más, ante las irregularidades detectadas en el proceso electoral en las últimas elecciones de Justicia y jurados. Lo que suponía la plena puesta en vigor del privilegio de 1459 y su confirmación durante las dos décadas siguientes. El rey confirmó el privilegio de elección durante veinte años, e introdujo un cambio en la elección de Clavario que no debía realizarse según la forma establecida en los privilegios anteriores, y se realizaría el 4 de febrero; el Justicia y los dos jurados elegían cuatro candidatos e introducian sus nombres dentro de un redolin en un bacín, el nombre contenido en el redolino extraído por un niño sería el nuevo Clavario (81).

En 1502 Fernando Il volvía a conceder a la villa de Alicante un privilegio electoral basado en el de 1459, renovándolo por diez años más (82). Después de la suspensión del privilegio electoral en 1508 (83) confirmó el privilegio en 1510 con algunas modificaciones, como la habilitación que debía realizarse cada tres años, en lugar de los cinco estipulados en el privilegio anterior. El nuevo privilegio recomendaba insacular a los nuevos pobladores casados y con casa en la villa (84).

\section{A MODO DE CONCLUSIÓN. LAS ALTERACIONES DEL SISTEMA POLÍTICO EN ALICANTE. INCIDENTES}

La mecánica electoral para dotar los cargos en la villa de Alicante sufrió diversos cambios, especialmente en el siglo XV, fruto de la política de reformas de la corona que tendía a un fortalecimiento del poder central a costa de la fragmentación de la personalidad administrativa y política de los municipios, en los que se originaron luchas fratricidas por el control del poder, que producian tensiones sociales en la villa, que quedaba a merced de la corona como único árbitro válido para solucionar las disputas internas. Esto se plasmó en una serie de incidentes que ilustran la arbitrariedad de la política seguida por los monarcas, y las fuertes tensiones sociales vividas en el seno del patriciado urbano alicantino. 


\subsection{Incidentes entre oficiales reales. Las injerencias de la Bailia}

La disputa que en 1446 se planteó entre el Baile general del reino de Valencia dellà Sexona y el Baile local de Alicante por las competencias de ambos sobre la designación del Justicia de la villa, refleja la arbitrariedad de la corona en su política sobre los municipios.

El 1 de diciembre de 1446 don Juan, rey de Navarra y lugarteniente general, escribía al Baile general del reino de Valencia dellá Sexona recomendando para las próximas elecciones de Justicia de Alicante a Jaume Bernat, como su candidato a la alta magistratura del municipio. Ordenaba al Baile que si en la terna que le presentaban aparecía Jaume Bernat, debía ser el designado (85). Seis días después pedía al Clavario de la Orden de Montesa mediación en el conflicto que mantenían el Baile general del reino de Valencia dellà Sexona y el Baile local de Alicante sobre la facultad de elegir al Justicia de la villa (86).

Las primeras manifestaciones, conocidas, de este conflicto se remontan al verano de dicho año, cuando ante el Consell de Orihuela se presentó Mosén Jaume Roca, Baile general de Orihuela. Alegó que en Valencia un hombre llamado Margarit, de la villa de Alcoy, le había presentado unas provisiones del rey por las que ordenaba que dicho Margarit, que era Baile local de Alicante, debía tener facultad sobre las regalías, derechos y emolumentos que en dicha villa había fiscalizado el Baile general. Roca actuó enviando a Jaume Rocamora, mensajero de Orihuela en Valencia, con la protesta pertinente ante don Juan, lugarteniente general, que anuló dicha provisión. Pero en el ínterin Margarit presentó a Pere Maça, Gobernador, una carta cerrada de dicho lugarteniente, por la que le ponía en posesión de la Bailía local y ordenaba realizar pregón público comunicando que a éste como Baile local y no al Baile general, correspondía la administración de las rentas, derechos y emolumentos del rey en la villa de Alicante. Relatados los incidentes, el Baile general comunicó al Consell de Orihuela que había enviado al procurador fiscal ante el Gobernador para presentarle la anulación que habia obtenido de don Juan, y para obtener copia de la carta que ordenaba realizar el pregón mencionado (87).

El Baile general ante el cariz que tomaban los acontecimientos, y la indecisión mostrada por el lugarteniente general sobre la resolución del conflicto que le afectaba, decidió recurrir al rey y aprovechando que una nave cargaba vinos en el puerto de Alicante con destino a Cerdeña y Nápoles, comunicó al Consell de Orihuela su decisión de enviar una carta al rey, que encomendó a unos capellanes que viajaban en la nave, suplicándole la conservación de las preeminencias que tenía sobre las rentas de Alicante (88). 
La respuesta del rey debió ser negativa a los intereses de Mosén Jaume Roca, al conceder el monarca a Margarit, la lugartenencia de la Baile general además del cargo de Baile local de Alicante que ya ostentaba, siguiendo la línea de fragmentación política efectuada por la corona a lo largo del siglo $X V(89)$.

En diciembre de 1448 don Juan volvía a designar su candidato para el cargo de Justicia de la villa de Alicante, pero a diferencia de la carta que envió dos años antes, ahora hacía su propuesta a los prohombres designados para nominar los candidatos al Justiciazgo (90) y a Joan Margarit Baile local de Alicante (91). Don Juan recomendaba a Francesch Puigvert que fue elegido y ejerció su cargo en 1449 (92).

Otra noticia, esta de 1464, nos informa sobre los vaivenes de la política real respecto a sus diversos oficiales. En una carta de Juan II a Mosen Jaume Roca, Baile general del reino de Valencia dellà Sexona, le comunica que está de acuerdo con la devolución y anulación que ha hecho de la elección de los oficios de Alicante y Guardamar, y que aprueba la designación de cargos que ha realizado (93). Si en 1448 correspondió al Baile local la nominación de cargos, en 1464 dicha potestad fue ejecutada por el Baile general que tenía facultad de derogar las elecciones si había observado alguna anomalía, en cuyo caso debía designar directamente los cargos. Estas actuaciones indiscriminadas de los respectivos oficiales reales debían repercutir en la normalidad institucional de la vida política municipal.

La vida municipal se veía mediatizada por las decisiones de la corona. En este caso ante la diferente actitud tomada por don Juan y Alfonso $V$, sobre la competencia del Baile general sobre la nominación del Justicia, que afectaba al normal desarrollo de la vida institucional, agravado por el hecho de que Juan II volvió a otorgar dicha competencia al Baile general, que en 1464 anulaba las elecciones y designaba directamente los cargos mermando de esta forma la autonomía municipal.

La mecánica electoral tenía como base la elección de los oficios municipales a través de un sistema de elección indirecto determinado por el azar, y en el que se tendía a impedir la intervención de las autoridades reales, regulada por fueros. El rey se reservaba la potestad de designar el oficial de la terna presentada por el municipio. En su ausencia el Baile general del reino designaba el elegido. Este intento de mantener la pureza del sistema se vio alterado por la intromisión de las autoridades reales, amparándose en la facultad de nominar un candidato de la terna, y en el derecho que tenian de suspender las elecciones si lo consideraban oportuno, alegando algún fallo en la ejecución de las mismas. 


\subsection{Las disputas en el seno de la oligarquia municipal}

La concesión a Alicante el 23 de abril de 1459 del nuevo régimen de gobierno (94), por el que la villa quedaba dotada con un mecanismo electoral por azar, más perfeccionado que el desarrollado hasta entonces, no puso fin a las disputas y fraudes, puesto que inmediatamente surgieron las complicaciones y protestas de un grupo de comerciantes y ciudadanos ante el incumplimiento de las funciones de la comisión de habilitadores. A esta comisión se le acusó de fraude y de haber realizado la elección de candidatos a las bolsas sin haber seguido el criterio estipulado en las nuevas ordenanzas, designando como candidatos a familiares, amigos, etc., pero sobre todo de no haber seguido los criterios de idoneidad exigidos al colocar en el saco mayor a personas «inhábiles", menores de edad, etc., y de haber colocado en el menor a las personas a las que correspondía por su condición social el mayor. Denunciaron también la inscripción en el saco menor de personas que no eran vecinas de la villa, lo que estaba prohibido por fueros (95), y especialmente la colocación en dicho saco de vizcaínos, franceses y portugueses a los que acusaban de ser extranjeros y de no hablar la lengua natural del país (96). El lugarteniente ante las quejas de los agraviados, aplicó una solución de concordia: una comisión elegida por el Justicia, jurados y Consell de Alicante, formada por tres hombres, uno del saco mayor, otro del menor y un tercero del grupo de los ocho habilitadores, se reuniría con don Juan, y junto a dos representantes de los querellados debían buscar una solución al conflicto. Si este grupo de tres hombres, no se presentaba ante él en un plazo no superior a cuatro días, atendería las quejas de Jaume Pérez y Jaume Esteve representantes de los agraviados.

Finalmente comparecieron Andreu Seva, por el saco mayor, Miguel Luqués por el menor, Melchor Vallebrera, del grupo de habilitadores y Juan Artés como mensajero del Consell. En la reunión con don Juan se llegó a una solución aplicando una serie de modificaciones al privilegio de abril. La más importante era la suspensión del capítulo que hacía referencia a la comisión de habilitadores y la anulación, por tanto, de la insaculación que habian realizado. El monarca sería ahora el encargado de designar los ocho miembros de la nueva comisión de habilitadores que el diecinueve de agosto del mismo año y ante el Consell general de la villa debían proceder a la insaculación pertinente (97).

En 1479 Fernando ll confirmaba el privilegio de 1477 durante veinte años más ante las irregularidades detectadas en el proceso electoral, en las últimas elecciones de jurados. De los dos jurados que se debian nominar tras 
su extracción de las bolsas, el Consell únicamente designó a uno como jurado, e inhabilitó a dos candidatos. La disolución del Consell, ante la falta de consenso en el proceso electoral, dejó a la villa sin jurados, por lo que quedó en suspenso la ordenanza electoral e intervino el Baile designando el segundo jurado. Los incidentes afectaron al Justicia que había sido elegido en las navidades pasadas, Bernat Pascual, y admitido por el Consell. Pero el rey fue informado que estaba acusado de ciertos crímenes, por lo que en la corte del monarca fue suspendido para seguir ejerciendo dicho oficio. El rey encomendó la magistratura a Miguel Salort.

Las actuaciones del Baile y el rey fueron, poco tiempo después, revocadas por el propio monarca, que ordenó aceptar como jurado al primer candidato inhabilitado y devolver el oficio de Justicia a Bernat Pascual, solicitando la renuncia al Justiciazgo de Miguel Salort.

Fernando Il confirmó de nuevo en 1479 el privilegio de 1477 durante veinte años. El rey se pronunció sobre los impedimentos puestos para desempeñar oficios a aquellos que hubiesen sido denunciados, excusa alegada para privar del oficio a determinados vecinos de la villa por sus rivales políticos, ordenando que si la denuncia no tenía sentencia definitiva, el denunciado podía desempeñar, no obstante la querella, cargo publico (98). 
(1) HINOJOSA MONTALVO, José. «El municipio valenciano en la edad media: características y evolución». Estudis Baleàrics, n. ${ }^{\circ}$ 23, Mallorca, 1989, pp. 39-59.

(2) GUIDI, Guidudalbo. II governo della città-republica di Firenze del primo Quatrocento. 3 vols, Firenze, 1981.

(3) Sobre el Justicia de Valencia vid. PÉREZ GARCIA, Pablo. «Origen y configuración de una magistratura urbana de la Valencia foral: El Justicia Criminal», Estudis, n. ${ }^{\circ} 13$, Valencia, 1987, pp. 21-73. NARBONA VIZCAINO, Rafael. «El Justicia Criminal. Una corte medieval valenciana, un procedimiento judicialm, Estudis Castellonencs, n. ${ }^{\circ} 3$. Castellón, 1986, pp. 287-310.

(4) Vid. ALANYA, Luis: Aureum opus regalium privilegiorum civitatis et regni Valentie. Valencia, 1515. Reimpr. facsimil, Valencia, 1972. Indices preparados por CABANES PECOURT, María Desamparados. (En adelante citado como $A O$ ).

(5) AO, Priv. LXXII de Jaime I. 1266, abril, 15. pp. 101-102.

(6) Furs de València. Llibre I. Rúbrica III. Fur XVIII Ed. a cura de G. COLON y A. GARCIA. Barcelona, 1970, vol. I. pp. 162-164.

(7) Cfr. nota.$^{\circ} 5$.

(8) AO, Priv. XIII de Pedro III. 1283, diciembre, 1. p. 121.

(9) NARBONA VIZCAINO, Rafael. Gobierno politico y luchas sociales. Estrategias de poder del patriciado urbano. La ciudad de Valencia. (1356-1419). Tesis doctoral inédita. Universidad de Valencia. Facultad de Geografía e Historia. 1988. 975 folios. Gentileza del autor.

(10) PÉREZ GARCIA, Pablo, «Origen y configuración...» p. 39.

(11) NARBONA VIZCAINO, Rafael. Gobierno politico...

(12) Furs de València. Llibre I. Rúbrica III. Fur XXVIII. Ed. cit. Vol. I. pp. 174-177 . En Valencia de los seis jurados, cuatro eran ciudadanos y dos caballeros. En Orihuela de los tres jurados, dos eran ciudadanos y uno caballero.

(13) A.H.N.E. Códice 1368-B, Privilegia per Serenissimos Reges civitati Oriole concessa, ff. 94r-95r. 1336, mayo, 17.

(14) PÉREZ GARCÍA, P., "Origen y configuración...», p. 52.

(15) ESTAL, Juan Manuel. Colección documental del Medievo Alicantino. Tomo II. 1306-1380. (Microforma). Alicante, 1988. doc. n. ${ }^{\circ}$ 55. 1311, febrero, 9.

(16) ESTAL, Juan Manuel. El Reino de Murcia bajo Aragón. (1296-1305). Corpus documental. Alicante, 1985, pp. 223-225. doc. n. ${ }^{\circ}$ 118. 1296, julio, 23.

(17) ESTAL, Juan Manuel. Colección documental..., doc. n. ${ }^{\circ} 42.1308$, junio, 17.

(18) ESTAL, Juan Manuel. Conquista y anexión de las tierras de Alicante, Elche, Orihuela y Guardamar al Reino de Valencia por Jaime II de Aragón. (1296-1308). Alicante, 1982, pp. 296 302; Colección documental..., doc. n. ${ }^{\circ}$ 45. 1308, junio, 25.

(19) PÉREZ PUCHAL, P. "La abolición de los Fueros de Valencia y la Nueva Planta», Saitabi, XII, Valencia, 1962, pp. 179-198. PESET REIG, M. «Apuntes sobre la abolíción de los Fueros de la Nueva Planta», I Congreso de Historia del País Valenciano. Valencia, 1973, Vol. III, pp. 525-536. 
(20) MARTINEZ MORELLA, Vicente. Cartas del Rey Don Juan I de Aragón, a Alicante. Alicante, 1953 , pp. $40-41$. doc. $n .{ }^{\circ} 20,1393$, febrero, 1 .

(21) Cfr. nota $n{ }^{\circ} 6$.

(22) PÉREZ GARCIA, Pablo. «Origen y configuración...»p. 66.

(23) Ibídem, p. 49.

(24) MART/NEZ MORELLA, Vicente. Libro antiguo de beneficios de la parroquial iglesia de Santa María de Alicante. 1300-1375. Alicante, 1954. Transcripción de traslados de testamentos realizados en el s/libre dels testaments» de la Corte de Alicante, validados por el Justicia de la villa.

(25) Furs de València. Llibre I. Rúbrica III. Fur XV. Ed. cit. Vol. I. pp. 160-161. PÉREZ GARCIA, Pablo. «Origen y configuración...», p. 50.

(26) AO, Priv. 24 de Alfonso IV. 1329, octubre, 24, ff. 84v-85r. pp. 228-229. A(rchivo) M(unicipal) de A(licante), Privilegios y Provisiones reales. Arm. 1, lib. 2, ff. 12r-13r. Traslado de 1383, abril, 11.

(27) A.M.O. Contestador, n. ${ }^{\circ} 25$, ff. $15 \mathrm{v} ;$ n. $^{\circ} 29, \mathrm{ff} .3 \mathrm{v} ; \mathrm{n} .{ }^{\circ} 30$, ff. $51 \mathrm{r}-54 \mathrm{v}$.

(28) ESTAL, Juan Manuel. Conquista y anexión..., p. 300.

(29) PÉREZ GARCIA, Pablo. «Origen y configuración...», p. 66.

(30) ESTAL, Juan Manuel. Colección documental..., doc. $n .{ }^{\circ} 45$.

(31) PÉREZ GARCIA, Pablo. “Origen y configuración...», pp. 67-69.

(32) A.M.O. Contestador, n. ${ }^{\circ} 25$, ff. 73r. 1445, octubre, 18.

(33) A(rchivo del) R(eino de) V(alencia), Real, n. ${ }^{\circ} 272$, ff. 19 r-v. 1448, junio, 17. PÉREZ GARClA, Pablo. "Origen y configuración...", p. 70.

(34) A.R.V. Real, 292, ff. 79v-80r. 1469, marzo, 29.

(35) PÉREZ GARCIA, Pablo. «Origen y configuración...», p. 59.

(36) A.R.V. Real, 110, ff. 14 r-v. 1471, enero, 25.

(37) A.R.V. Real, 109, ff. 69v-70r. 1471, junio, 4. Real, 109, ff. 69v-70r. 1471, junio, 4. Real, 110, ff. 54v-55r, 1471, junio, 4. En la causa seguida por la muerte de Nicolau Nomdedeu se concedió comisión al Baile general reino de Valencia dellà Sexona y al Justicia de Orihuela, que debían actuar con el asesoramiento judicial de dos expertos, Nicolau Aster y Francesch Vilafranca, juristas. A.R.V. Real, 109, ff. 73v-74r. 1471, junio, 4. Y en la causa seguida contra ciertos vecinos de Alicante por romper la "sala" de Alicante y entrar en áquella por las ventanas, sacando a Nicolau Domenech de la prisión.

(38) PÉREZ GARCÍA, Pablo. «Origen y configuración...".

(39) A.R.V. Real, 111, ff. 6 r-v. 1474, septiembre, 28.

(40) BERNABÉ GIL, David. Elites de poder y administración municipal en una ciudad valenciana: Orihuela en la época foral moderna. Tesis doctoral inédita. Universidad de Alicante, 1988, 1179 folios. Gentileza del autor, ff. 48-49.

(41) BÉRNABE GIL, Davíd. Elites de poder..., f. 74. CABANES CATALA, María Luisa. El «Llibre del "mustaçaf" de la ciutat d'Alacant". Alicante, 1989.

(42) A.R.V. Real, 40, ff. 16v-17r. 1426, febrero, 13.

(43) PÉREZ GARCIA, Pablo. "Origen y configuración...", p. 40.

(44) Sobre competencias del Mustaçaf en Alicante. Vid. CABANES CATALA, María Luisa. EI "Llibre del "Mustaçaf"'"...

(45) A.R.V. Real, 111, ff. 175v. 1477, mayo, 10.

(46) A.R.V. Real, 302, ff. 123 r-v. 1479, agosto, 13.

(47) A.R.V. Real, 99, ff. 112 r-v. 1464, junio, 25. Real, 99, ff. 116v. 1464, junio, 25. Real, 99, ff. $116 v-117 r .1464$, junio, 25.

(48) A.R.V. Real, 303, ff. 15r-17r. 1479, junio, 15.

(49) ALBEROLA ROMA, Armando. «Un funcionario de la hacienda foral Valenciana: El Racional de Alicante. Apuntes para su estudio", Fiscalitat estatal i hisenda local (ss. XVI-XIX): Funcionament i repercusions socials. Mallorca, 1988, pp. 127-137.

(50) BERNABÉ GIL, David. Élites de poder..., f. 74 GLICK, Thomas F. Regadio y sociedad en la Valencia medieval. Valencia, 1988. 
(51) A(rchivo) de la C(orona) de A(ragón), Cancilleria, Reg. 1677, ff. 113v-114v. 1368, enero, 28.

(52) A.C.A. C, Reg. 1686, ff. 221r-222r. 1382, octubre, 22.

(53) A.C.A. C, Reg. 946, ff. 69 r-v. 1386, enero, 10.

(54) PÉREZ GARCÍA, Pablo. «Origen y configuración...», pp. 36 y 41.

(55) A.R.V. Real, 111, ff. 9r-10v. 1474, septiembre, 28.

(56) Ibídem, p. 35.

(57) Ibidem, p. 55-56.

(58) A.R.V. Real, 40, ff. 16v-17r. 1426, febrero, 20. Confirmación de 1407, noviembre, 23.

(59) A.R.V. Real, 40, ff. 14r-15r. 1426, febrero, 13. A.M.A. Privilegios y Provisiones reales. Arm. 1, lib. 2, ff. $84 \mathrm{r}$-v.

(60) En Florencia existian una serie de limitaciones para desempeñar cargos similares a las existentes en el área valenciana. Vid. GUIDI, Guidubaldo. II governo..., Vol. I, pp. 99-138.

(61) Vid. ALBEROLA ROMA, Armando. "Estudio preliminar» en Ordenanzas..., Cfr. nota n. ${ }^{\circ} 63$. A.R.V. Real, 287, ff. 62r-63v. 1461, noviembre, 6. PATERNINA, María Jesús. Transcr. en Ordenanzas..., pp. 61-66.

(62) El Llibre blanch de la Governació. ff. 100r-101v. 1467, agosto. 8. Ed. preparada por PEREZ PÉREZ, Desamparados. Valencia, 1971, pp. 191-196.

(63) ESTAL, Juan Manuel. Alicante de villa a ciudad (1252-1490). Alicante, 1990. pp. 261-262. Doc. $n .^{\circ} 98.1305$, mayo, 17. 64. Vid nota n. ${ }^{\circ}$ 15. Un documento de 1311 nos informa que en Orihuela hasta esa fecha, la confirmación del Justicia, en ausencia del rey, la realizaba el Baile general del reino de Valencia dellà Sexona, por lo que deducimos que igual confirmación se debió realizar en Alicante. No tenemos constancia para la villa de Alicante, de un privilegio similar al que recibió Orihuela, facultando al Baile local de esta localidad a realizar la nominación del Justicia. Pero creemos que fue un privilegio del que no disfrutó Alicante por la pugna suscitada en 1448 entre el Baile local de Alicante y el Baile general dellà Sexona, al intentar este último mantener sus preeminencias y derechos sobre la villa de Alicante en detrimento del Baile local de esta localidad. El privilegio de 1311 podia suponer un reconocimiento más a la capitalidad de Orihuela sobre la nueva división administrativa creada por Jaime II.

(65) AO, Priv. XIII de Alfonso IV. 1329, mayo, 11.

(66) Sobre las luchas entre facciones opuestas por el poder municipal. BATLLE GALLART, Carmen. La crisis social y económica de Barcelona a mediados del siglo XV. Barcelona, 1973. Ibídem, "La "Busca". Aspectos de la reforma municipal de Barcelona", Homenaje a Jaime Vicens Vives. Vol. I, Barcelona, 1965, pp. 337-350. Ibídem, «Una familia barcelonesa: los Deztorrent», Anuario de Estudios medievales, n. ${ }^{\circ}$ 1, Barcelona, 1964, pp. 471-488. Ibídem, «La oligarquía de Barcelona a fines del siglo XV: el partido de Deztorrent», Acta histórica et archaeologica medievalia, n. 0 7-8, Barcelona, 1986-1987, pp. 321-335.

(67) ESTAL, Juan Manuel. Colección documental..., Doc. n. ${ }^{\circ} 55$.

(68) ALBEROLA ROMA, Armando. HINOJOSA MONTALVO, José. «La instauración del sistema insaculatorio en los territorios meridionales del País Valenciano. Alicante, 1459». Actas del Congrés de Lluís de Santángel i el seu temps, València, octubre de 1987, en prensa. ALBEROLA ROMA, Armando. «Estudio preliminar», en Ordenanzas municipales. Alicante 1459-1669. Alicante, 1989.

(69) HINOJOSA MONTALVO, José. «EI municipio valenciano...", ALBEROLA ROMA, Armando. «Un funcionario...», Ibídem: «Aproximación al régimen municipal valenciano en la primera mitad del siglo XVI: el caso de Alicantes Hernán Cortés y su tiempo. Onteniente, 1987, Volumen II. pp. 603-607. ALBEROLA ROMA, Armando. HINOJOSA MONTALVO, José. "La instauración..."; ALBEROLA ROMA, Armando. "Estudio preliminar», en Ordenanzas municipales...; BERNABE GIL, David. «Centralismo y autonomia municipal en Orihuela: De Fernando el Católico al "viraje Filipino"", Estudis. n. ${ }^{12}$, Valencia, 1986, pp. 29-53. BERNABE GIL, D. Elites de poder...; SOBREQUÉS I VIDAL, Santiago. «EI régim municipal de Girona a la Baixa Edat Mitjana», en Societat i estructura política de la Girona Medieval. Barcelona, 1975. TORRAS I RIBE, J.M. Els municipis catalans de l'Antic Règim. (1453-1808). 
Barcelona, 1983. Ibídem: «El procediment electoral per insaculació en el municipi d'Igualada. (1483-11714)», Miscellanea Aqualatensia, n. ${ }^{\circ} 3$, Igualada, 1983, pp. 101-131. VICENS VIVES, Jaime. Ferran II i la ciutat de Barcelona. (1479-1576). Barcelona, 1937. 3 vols.

(70) A.C.A. C, reg. 2698, ff. 160v. 1446, febrero, 7.

(71) A.R.V. Real, 283, ff. 74r-75r. 1459, julio, 18.

(72) Vid. ALBEROLA ROMA, Armando. "Estudio preliminar", en Ordenanzas..., Cfr. nota n. ${ }^{\circ}$ 63. A.R.V. Real, 287, ff. 62r-63v. 1461, noviembre, 6. PATERNINA, María Jesús. Transcr. en Ordenanzas..., Doc. n. ${ }^{\circ} 2$, pp. 61-66.

(73) A.M.O. Contestador n. ${ }^{\circ} 30$,ff. 49 r-v. 1455, diciembre, 21.

(74) A.R.V. Real, 408, ff. 187 r-v. 1468, mayo, 21.

(75) BELENGUER CEBRIÁ, E. València en la crisi del segle XV. Barcelona, 1976. HINOJOSA MONTALVO, José. «EI municipio valenciano...», A.C.A. C, 2698, ff. 151v-152r. 1466, febrero, 26. Ceda enviada por el rey a la ciudad de Valencia para la elección de jurados del año 1446, incluye quince caballeros e igual número de ciudadanos. A.C.A. C, 2698, ff. 161v162r, 1446, febrero, 18. Ceda para la elección de Racional, Abogados, Síndico y Escribano de la sala, incluye un nombre para cada oficio, excepto tres para los abogados, lo que suponia la designación directa de los mismos. A.C.A. C, 2699, ff. 74r. 1477, mayo, 2. Cédula para la elección de jurados del año 1477, incluye doce caballeros y doce ciudadanos.

(76) HINOJOSA MONTALVO, José. «El municipio valenciano...», p. 43.

(77) A.R.V. Real, 110, ff. 58 r.v. 1471, mayo, 14.

(78) CABEZUELO PLIEGO, José Vicente. Documentación alicantina en el Archivo de la Corona de Aragón durante el reinado de Pedro IV el ceremonioso. 1355-1370. Memoria de licenciatura inédita. Alicante, 1989. Doc. n. ${ }^{\circ} 81$. 1370, junio, 7. Gentileza del autor.

(79) Vid. ALBEROLA ROMA, Armando. "Estudio preliminar» en Ordenanzas..., p. 24. PATERNINA, María Jesús. Transcr. en Ordenanzas..., Doc. n. ${ }^{\circ} 3.1477$, mayo, 9. pp. 67-71.

(80) ARQUES JOVER, A. Fr. Nobiliario alicantino. Transcripción y notas de MAS Y GIL, L. Y ESCUDERO RIBERA, J.M. Alicante, 1966. BARON DE FINESTRAT. Nobiliario alicantino. Alicante, 1983. Aluden a una insaculación de 1476 de la que no tenemos noticia. Pero la referencia a los nueve habilitadores coincide con la insaculación ordenada realizar en 1477 , por lo que pensamos en un posible error cronológico, que se confirma al comprobar la fecha de la habilitación señalada, del 22 al 24 de mayo de 1476, no corresponde a la víspera de Pentecostés, cuando se debía realizar la habilitación, ya que en 1476 Pentecostés se celebró el 2 de junio, mientras que en 1477 correspondió a un 25 de mayo. $Y$ coincide con la fecha estipulada en el privilegio de 9 de mayo de 1477 . Vid. nota $n .^{\circ} 79$.

(81) A.R.V. Real, 303, ff. 15r-17r. 1479, julio, 15

(82) Cfr. nota n. ${ }^{\circ}$ 63. PATERNINA, María Jesús, Transcr. en Ordenanzas..., pp. 73-86.

(83) REGLA, Juan. «Notas sobre la política municipal de Fernando el Católico en la corona de Aragón», Homenaje a Jaime Vicéns Vives. Barcelona, 1967, Vol. II. pp. 521-533.

(84) MARTÍNEZ MORELLA, Vicente. Privilegios y provisiones de Fernando el Católico a Alicante. Alicante, 1951, Doc. $n^{\circ}$ 9. 1510, enero, 4.

(85) A.R.V. Real, 70, ff. 29v. 1446, diciembre, 1.

(86) A.R.V. Real, 70, ff. 35 r-v. 1446, diciembre, 7.

(87) A.M.O. Contestador, n. ${ }^{\circ} 27, \mathrm{ff}, 87 \mathrm{v}-89 \mathrm{r}, 1446$, agosto, 14.

(88) A.M.O. Contestador, ${ }^{\circ}{ }^{\circ} 27$, ff. 112r. 1446, octubre, 23

(89) A.M.O. Contestador, ${ }^{\circ}{ }^{\circ} 27$, ff. 5 v. 1477 , marzo, 1.

(90) A.R.V. Real, 272, ff. 56v-57r. 1448, diciembre, 19.

(91) A.R.V. Real, 272, ff. 57r. 1448, diciembre, 19.

(92) ARQUES JOVER, A. Fr. Nobiliario..., p. 126.

(93) A.R.V. Real, 243, ff. 2r. 1464, enero, 27.

(94) PATERNINA, María Jesús. Transcr. en Ordenanzas...

(95) Furs de València. Llibre I. Rúbrica III. Fur XVIil. Ed. cit. Vol. I, pp. 162-164.

(96) A.R.V. Real, 280, ff. 125r-126r. 1459, junio, 30.

(97) A.R.V. Real, 283, ff. 74r-75r. 1459, julio, 18.

(98) A.R.V. Real, 303, ff. 15r-17r. 1479, julio, 15; 303, ff. 46v-47rbis. 1479, agosto, 17. 